\title{
Preface
}

\section{to the Second Edition}

Since Unequal Childhoods was published, the children in the book have passed through childhood and adolescence into adulthood. At the end of the study, I had wanted to know how the lives of these children would unfold. I was particularly interested to see if the patterns of class differences in child rearing would continue over time. Thus, approximately ten years after the original study, when the youth were between the ages of nineteen and twenty-one, I revisited the twelve families who were in the intensive study. In this second edition of the book, I report the findings from the follow-up study. Three new chapters on these findings are added as Part IV, followed by a brief Afterword. Also included are an additional table in Appendix C, a new Appendix D, and a revised bibliography. The material from the first edition remains unchanged.

\section{ACKNOWLEDGMENTS}

The process of moving to a second edition of Unequal Childhoods had a number of challenges, but I was also greatly blessed with intellectual, social, and material support. The Spencer Foundation gave generous financial assistance for the project. My program officer, Susan Dauber, deserves particular thanks. While all errors are my own responsibility, I remain deeply indebted to the Spencer Foundation for the ways in which they made the project possible. Temple University, the University of Maryland, and the University of Pennsylvania all provided much-appreciated institutional support. The Institute for the Advanced Study of the 
Behavioral Sciences in Stanford, California, gave me an intellectual home during 2005-6. Dalton Conley graciously supplied office space at New York University at a critical point in the study. My writing group members, Erin McNamara Horvat and Demie Kurz, gave me indispensable feedback. Patricia Berhau had a crucial position in the original study and also in the data analysis of the follow-up study. It is hard to convey the depth of my gratitude to Elliot Weininger for his immeasurable contributions. I also owe a special debt to Amanda Cox for her conversations, coding work, and collaboration. Indeed, the separate essays I coauthored with Elliot Weininger and with Amanda Cox helped to develop many of the points I discuss here; Chapter I3, in particular, includes material from these joint works. Audiences at a number of institutions, especially George Mason University, the University of California San Diego, Northwestern University, Franklin and Marshall, Harvard University, the University of California Los Angeles, New York University, and the University of Pennsylvania, provided helpful feedback as I sought to develop the ideas presented here. Many others, including readers, also have helped me develop my thoughts. From lively exchanges to highly critical feedback, I have benefited particularly from the input of the following people: Michael Bader, Harry Brighouse, Jessica McCrory Calarco, Dalton Conley, Maia Cucchiara, Andrew Deener, Mitch Duneier, Frank Furstenberg, Flo Gelo, Michèle Lamont, Ralph LaRossa, Robin Leidner, Katherine McClelland, Bud Mehan, Vanessa Lopes Muñoz, Wes Shumar, Lisa Smulyan, Amy Steinbugler, Karolyn Tyson, Melissa Velez, Pamela Barnhouse Walters, Melissa Wilde, Julia Wrigley, Tina Wu, and my monthly reading group. My editor, Naomi Schneider, aided significantly in moving the project to closure.

It is common for students to be unaware of how much professors learn from them. Students in my courses at the University of Pennsylvania and the University of Maryland have given me useful feedback. Andrew Cherlin and Arlie Hochschild both graciously had their graduate classes read the material, which produced many helpful comments. Shani Evans and April Yee provided valuable research assistance, as did Pamela Ellerman, Rebecca Holtz, and, especially, Alina Tulloch. M. Katherine Mooney also has played an exceptional role as friend, critical reader, and editor. As always, my children by marriage, Dillon and Rachel, helped to distract me from the demands of work. My husband, Samuel Freeman, provided laughter and comfort as the project inched forward. Finally, I am very grateful to the families in the study for their many contributions and their willingness, in most instances, to remain in conversation despite moments of difficulty. 